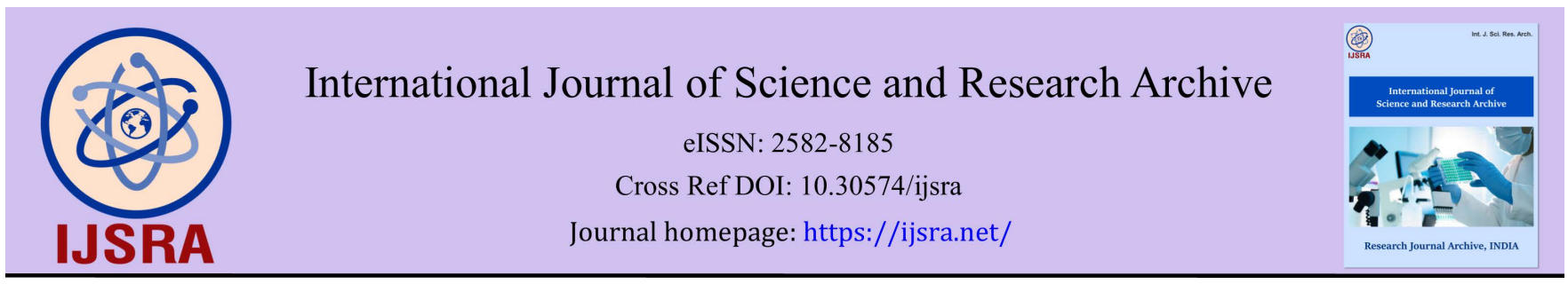

(RESEARCH ARTICLE)

\title{
Effects of the COVID-19 pandemic on radiography education in Nnamdi Azikiwe University, Nigeria
}

Michael Sunday Okpaleke ${ }^{1, *}$, Christopher Chukwuemeka Ohagwu ${ }^{1}$, Chigozie Ivor Nwobi ${ }^{2}$, Michael Promise Ogolodom ${ }^{1}$, Victor Kelechi Nwodo ${ }^{1}$ and Uche Nathaniel Eja-Egwu ${ }^{1}$

${ }^{1}$ Department of Radiography, and Radiological sciences, Nnamdi Azikiwe University, Okofia, Nnewi town, Nigeria.

${ }^{2}$ Department of Radiography, University of Maiduguri, Maiduguri Township Nigeria.

International Journal of Science and Research Archive, 2021, 03(01), 082-092

Publication history: Received on 12 June 2021; revised on 28 July 2021; accepted on 30 July 2021

Article DOI: https://doi.org/10.30574/ijsra.2021.3.1.0104

\begin{abstract}
COVID-19 pandemic shutdown of tertiary institutions in Nigeria and globally following the lockdown of socio-economic activities. There is paucity of data on the effects of the pandemic on Radiography education in Nigerian universities especially in Nnamdi Azikiwe University (NAU) Nnewi campus. This prospective cross - sectional study was carried out using a structured questionnaire. One hundred and twenty- five questionnaires were distributed by the researcher to students, academic and non-academic staff of the department of Radiography, NAU, and one hundred was retrieved thereafter. Descriptive and inferential statistics were used for data analysis using statistical package for social sciences (SPSS) version 23 at $5 \%$ level of significance. The major effects of the COVID-19 pandemic on Radiography education in NAU were poor access to education financing (97\%), poor attendance to lectures (91\%), poor academic performance after the lockdown (85\%), better attitude to infection control (81\%), disruption of academic calendar (88\%), the rushing of many lectures over a short time and low assimilation/understanding among students (75\%), the predominance of physical classroom lectures especially among undergraduates (55\%), promoted online lectures especially among postgraduate students (45\%), better hygiene culture $(35 \%, 0.00076=\mathrm{p}<0.05$, adjusted $\alpha=0.0032)$ ) and loss of interest in education (27.5\%). However, only the enthronement of better hygiene culture had significant effects on Radiography education ( $p=0.00076)$. The study concludes that the only significant and positive effect of COVID-19 pandemic on Radiography education in NAU was the enthronement of better hygiene culture.
\end{abstract}

Keywords: COVID-19; Pandemic; Effects; Radiography Education

\section{Introduction}

\subsection{COVID-19: Etiology, Transmission and Mortality}

The sudden outbreak of coronavirus disease (COVID-19) which was reported in Wuhan province in China in December 2019 caught the attention of the world by surprise as it spread across the borders of various nations without control [1]. Epidemiological and genetics researches indicate that the COVID-19 disease is caused by Severe Acute Respiratory Syndrome Coronavirus- 2 (SARS - CoV -2) which started with an animal to human transmission followed by human to human transmission [2]. Globally, as of 11:13 CEST, 29 April 2021, there have been 148,999,876 confirmed cases of COVID-19 including 3,140,115 deaths reported to the WHO out of which the total confirmed cases in Nigeria was 164,448 and 2061 deaths [3]. This number is expected to rise globally with Africa and indeed Nigeria bearing the greater burden of the disease as the Pandemic currently ravages the state of India and the rest of the world [3] with the mutation of more deadly stains of the virus. Since the index case of COVID-19 was recorded in Lagos, Nigeria in February 2020, the number of persons infected by the COVID-19 viruses has continued to rise daily and almost all the states in the

\footnotetext{
* Corresponding author: Michael Sunday Okpaleke

Department of Radiography, and Radiological sciences, Nnamdi Azikiwe University, Okofia, Nnewi town ,Nigeria.
} 
federating units of Nigeria has its own fair share of coronavirus infections. These trends according to experts indicate a progressive and sustained community transmission which must be checked [4]. Once infected, the peculiar clinical symptoms of COVID-19 which may or may not manifest include, fever, cough, fatique, lung injuries/pneumonia, pulmonary oedema, nervous, gastrointestinal and cardiovascular disorders while congestion, rhinorrhea, sore throat and are rare [5]. These symptoms either acting in isolation or in group if untreated could lead to sudden death. The infection fatality rate was high in Wuhan, China, India, Italy, Britain, France, the United States of America amongst other locations in the world due to initial poor COVID-19 disease management resulting in widespread nosocomial infections and deaths. Poor decisions of sending COVID-19 patients to nursing homes, wrong use of ventilators and hydoxychloroquine as well as congestion of people in public and commercial places such as public transportation systems, religious places, schools, played significant roles in exposing people to high loads of COVID-19 infection. The emergences of mutant strains of the virus including the Delta Variants have worsened prognostic outcomes. These resulted in high COVID-19 infection fatality rate and deaths especially in China, Europe and India [6]. The COVID-19 pandemic led to the shutdown of tertiary and other educational institutions as well as the lockdown of socio-economic activities globally and in Nigeria.

COVID-19 disease affects both old and young people but the infection and the mortality rate of COVID-19 is more severe in the older generation especially those individuals with underlining diseases such as cardiovascular diseases, hypertension, diabetes, HIV, and other immune-compromising diseases and affecting more males than females [7]. The COVID-19 pandemic which is a droplet infection is the greatest health crisis the world have ever seen in the last 100 years with associated educational, socio-economic, and health implications. It was the greatest test being faced by the United Nation since its formation [8].

\subsection{International and Local Responses to COVID 19 Pandemic and Challenges}

To surmount the challenges faced by the pandemic various national governments took far-reaching measures to contain the rapid spread of the virus. They adopted several media campaigns and other measures that modified their health systems response to the pandemic. In Nigeria, the government responded by providing public health education and risk communication campaigns using both conventional and unconventional methods of disseminating information through the radio, televisions, print media, and social media handles like Twitter, whatsApp, and Facebook to appeal to the public. The presidential task force (PTF) on COVID-19 was established on $9^{\text {th }}$ March 2020 to coordinate and overseer the activities of different sectors of the economy as well as inter-governmental efforts toward the containment of the COVID-19 outbreak in Nigeria. The National Centre for Disease Control (NCDC) created the national coronavirus preparedness group (NCPG) which was multi-sectoral in nature to review COVID - 19 epidemiology, risks associated with the disease as well as strengthen Nigeria's readiness for early testing, detection, and management of COVID-19 outbreak in Nigeria. Following the outbreak of COVID - 19 in Nigeria, the NCPG was renamed the National Multisectoral Emergency Operations Centre with additional functions but not limited to research, COVID 19 coordination, surveillance, logistics, and laboratory testing at point of entry (PoE). The NCDC, federal and state governments also activated molecular biology and isolation centers in different parts of the country for the containment of the disease [9]. The NCDC used effective media communication strategy with the slogan 'take responsibility' as part of COVID-19 awareness for Nigerians' [10]. Despite the national and global efforts towards mitigating the negative effects of COVID19 , the disease caused extensive damage to the social, economic and educational systems of many nations such as Italy, the United States of America, France, the United Kingdom, India, South Africa, and Nigeria. The extent to which Radiography education in Nigerian universities have been affected by the COVID -19 pandemic is yet to be fully understood. This paper therefore $\mathrm{x}$-rayed the effects of COVID-19 pandemic on Radiography education in a renowned Nigerian University, the Nnamdi Azikiwe University Nnewi campus.

COVID -19 pandemic is a global challenge that requires concerted efforts of governments at various levels, scientists and policymakers to address the complex multifaceted challenges and fallouts of the disease [1, 6, 8]. The COVID -19 pandemic despite bringing cleaner urban air temporarily also brought socio-economic lockdowns and movement restrictions. The global response to the coronavirus pandemic also resulted in economic recessions, public health issues such as increased hunger and malnutrition, obesity, chronic health conditions, as well as the crisis in the education sector $[3,5,6,7]$. Another major challenge to the global response was the inability of scientists and the World Health Organization to quickly develop and supervise the distribution of free vaccines for general immunization during the early days of the pandemic. This would have gone a long way to arrest the spread of the COVID-19 virus and prevent community transmission.

Nigeria's response to COVID-19 outbreak was bedeviled by low testing capacity making it difficult to ascertain the exact individuals who are at risk of the disease, inadequate / poorly coordinated diagnostic laboratory networks with low capacity to handle sample volumes and movement of samples from one location to another. Other challenges include 
poorly equipped isolation centers, poor tracking/tracing as well management of infected persons, stigmatization of infected individuals, corruption, poor and uncoordinated disbursement of COVID-19 palliatives to Nigerians, negative religious belief on the COVID-19 pandemic, lack/inadequate supply of clean water for regular hand washing, high cost of alcohol-based sanitizers, inadequate deployment of personnel protective equipment (PPE), inadequate training, remuneration and motivation of health professionals [7]. The problem created by insecurity ranging from terrorism, activities of bandits, unknown gunmen, and kidnappers in different parts of Nigeria resulting in the destruction of health facilities, abduction and death of health personnel's also hampered efforts of Government and non-governmental agencies in the control and management of COVID-19 pandemic [11].

Furthermore, Nigeria is one of the thirteen African countries categorized by the World Health Organization (WHO) as being at high risk for the COVID-19 pandemic. In fact, Nigeria can be regarded as been very vulnerable considering the poor state of health facilities in the country to the extent that some communities and universities lack access to basic healthcare services or where they are available are sourced at a very high cost [12]. Also, decades of neglect and poor funding of the fragile health sector explains the high mortality in Nigeria and other countries. Also the sidelining of expertise knowledge in communicable disease control by some national governments in the UK and USA to setting up of tasks forces and committees, centralizing and privatizing the response to COVID-19 failed to deliver on targets [13]. These amongst other factors led to the introduction lockdown of socio-economic activities across the globe and restriction of free movements of people thereby worsening the already existing inequalities in our society especially for girls and women of child-bearing age as well as increased the discrimination of some vulnerable and marginalized groups of individuals [14]. In Nigeria, the federal and various state governments announced curfews and lockdown on movements and economic activities to curtail the spread of the COVID-19 infections. The partial and total lockdown/curfews including the closure of all educational institutions were enforced to prevent and limit community spread of the Coronavirus pandemic. Students from primary to tertiary levels of education were out of school as a result of the lockdown to prevent community transmission and ensure that people adhere to safety directives on social distancing, hand washing/sanitizing of hands as well as the use of face masks. The lockdown /curfews had some negative consequences on the population that led the outcry for its cancellation. It was observed that majority of the population were daily income earners who work in the informal sector and are very vulnerable. The lockdown pushed many Nigerians out of the classrooms as students. According to UNESCO, more than 45 million students from primary to tertiary schools in Nigeria were out of school during the lockdown that lasted several months and this led many into poverty, unemployment and may have initiated a surge in insecurity, prostitution, unwanted/teenage pregnancy, kidnapping, robbery, rape and other social vices $[1,15]$. Unfortunately, some students became exposed to some of these vices because they were out of school. Also, apart from the missed opportunities to learn at school during the lockdown, most students lost access to important services provided by the schools such as the school feeding program of the federal government which provided access to healthy nutrition, social protection, and safety nets for millions of students nationwide. When the schools were about to be opened, there were debates as to whether tertiary institutions should open without the primary and secondary schools or that all should open at the same time in phases. However, when the schools eventually opened, there were challenges and modifications in teaching and learning in order to contain the pandemic. There is a strong positive relationship between accesses to education at all levels and 26\% expenditure on education. It has been reported that $26 \%$ expenditure on education will impact tertiary education 9- times [16]. Despite not meeting this international benchmark, the Nigerian government still reduced the monetary allocation for education from $6.7 \%$ of the national budget in 2020 to $5.6 \%$ in 2021 . The 2021 education budget was the lowest budgetary allocation to the education sector since 2011. Although analysts have attributed these poor allocations to the COVID-19 pandemic and rising national borrowing in addition to increasing cost of external debt servicing [17] amongst other factors. This implies that medical education and indeed Radiography education and research in Nigeria will be affected. These statistics worsened the fragile health system and poor infection control preparedness of the Nigerian health system which necessitated the implementation of health-related safety measures as well as modifications to methods of teaching and learning with its challenges and implications for Radiography education in Nigeria. Literature is averse with works on the effect of the COVID-19 pandemic on the economy, social life, education and professional Radiography training but none has evaluated the effects of the COVID-19 pandemic on university-based Radiography education in Nigeria [18]. This paper, therefore, assessed the effects of the COVID-19 pandemic on Radiography education in Nnamdi Azikiwe University, Nigeria.

\section{Material and methods}

The study adopted a cross-sectional prospective research survey using questionnaires. The structured questionnaire was divided into two sections namely section A and section B. The items in Section A were used to collect the participants' socio- demographic data such as age, gender, marital status, and educational status. Section B of the questionnaire evaluated the effects of the COVID-19 pandemic on Radiography education in Nnamdi Azikiwe University, Nigeria. The items in the questionnaire were reviewed by a panel of two experts for reproducibility and validity of 
measurements. Items were included if they meet the scale content validity index (S-CVI) score of $>0.78$ [19]. Using the $\mathrm{S}$-CVI of 0.78, a total of 4 and 25 questions were included in sections A and B of the questionnaire respectively. The questionnaire thereafter returned an average reliability coefficient of 0.71 using the Cronbach alpha and Kuder Richardson (KR) - 20 tests [20]. A total of one hundred and twenty-five questionnaires were distributed to students, academic and non-academic staff of the Department of Radiography, Nnamdi Azikiwe University Nnewi campus. Descriptive and inferential statistics were used for analyzing the questionnaires at a $5 \%$ level of significance using the statistical package for social sciences (SPSS) version 23.

\section{Results}

One hundred out of one hundred and twenty-five questionnaires distributed to respondents (mean age: $29.98 \pm 12.10$ ) were completed and returned. Seventy -two percent $(n=72)$ of the respondents were in the age range of 18-29 years and were undergraduates (table 1).

Table 1 Age and educational status of respondents

\begin{tabular}{|c|c|c|c|c|c|c|}
\hline \multirow{2}{*}{$\begin{array}{l}\text { Age } \\
\text { range } \\
\text { (years) }\end{array}$} & \multicolumn{4}{|c|}{ Educational status of respondents } & \multirow{2}{*}{$\begin{array}{l}\text { Total } \\
\text { n(\%) }\end{array}$} & \multirow[b]{2}{*}{ Mean \pm sd } \\
\hline & $\begin{array}{l}\text { Undergraduate's } \\
\text { students } n(\%)\end{array}$ & $\begin{array}{l}\text { Postgraduate's } \\
\text { students n(\%) }\end{array}$ & $\begin{array}{l}\text { Lectures } \\
\text { n(\%) }\end{array}$ & $\begin{array}{l}\text { Non - academic } \\
\text { staff } n(\%)\end{array}$ & & \\
\hline $18-29$ & $67(67 \%)$ & $3(3 \%)$ & $2(2 \%)$ & - & $72(72 \%)$ & $27.45 \pm 7.93$ \\
\hline $30-41$ & - & $7(7 \%)$ & $1(1 \%)$ & $5(5 \%)$ & $13(13 \%)$ & $24.23 \pm 3.49$ \\
\hline $42-53$ & $2(2 \%)$ & - & $2(2 \%)$ & $3(3 \%)$ & $7(7 \%)$ & $31.00 \pm 11.79$ \\
\hline $54-65$ & $1(1 \%)$ & $1(1 \%)$ & $1(1 \%)$ & $1(1 \%)$ & $4(4 \%)$ & $54.25 \pm 1.26$ \\
\hline$>66$ & - & - & $2(2 \%)$ & $2(2 \%)$ & $4(4 \%)$ & $68.00 \pm 1.83$ \\
\hline $\begin{array}{l}\text { Total } \\
(\mathrm{n} / \%)\end{array}$ & $70(70 \%)$ & $11(11 \%)$ & $8(8 \%)$ & $11(11 \%)$ & $\begin{array}{l}100 \\
(100 \%)\end{array}$ & $29.98 \pm 12.10$ \\
\hline
\end{tabular}

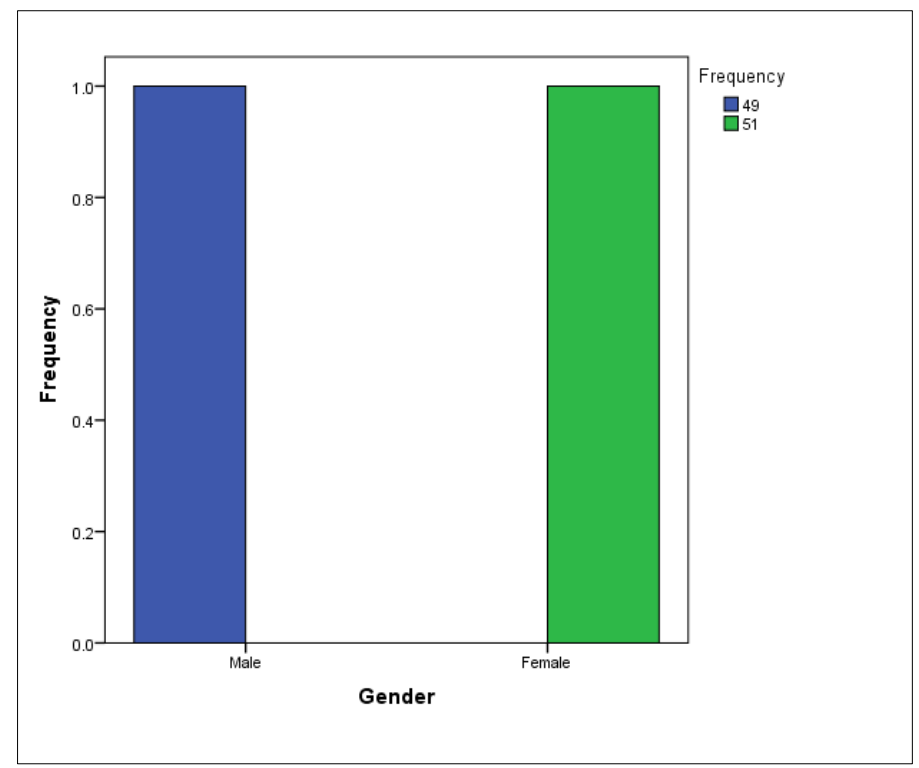

Figure 1 Gender distribution of the respondents

Post-graduate students, lecturers and non-academic staff constitute $11 \%, 8 \%$, and $11 \%$ of the respondents respectively. The respondents consist of $49 \%$ and $51 \%$ males and females respectively (figure 1 ) 
Eighty eight percent $(n=88)$ of the respondents confirmed that their academic calendar or academic session was disrupted/delayed because of the COVID 19 pandemic (figure 2).

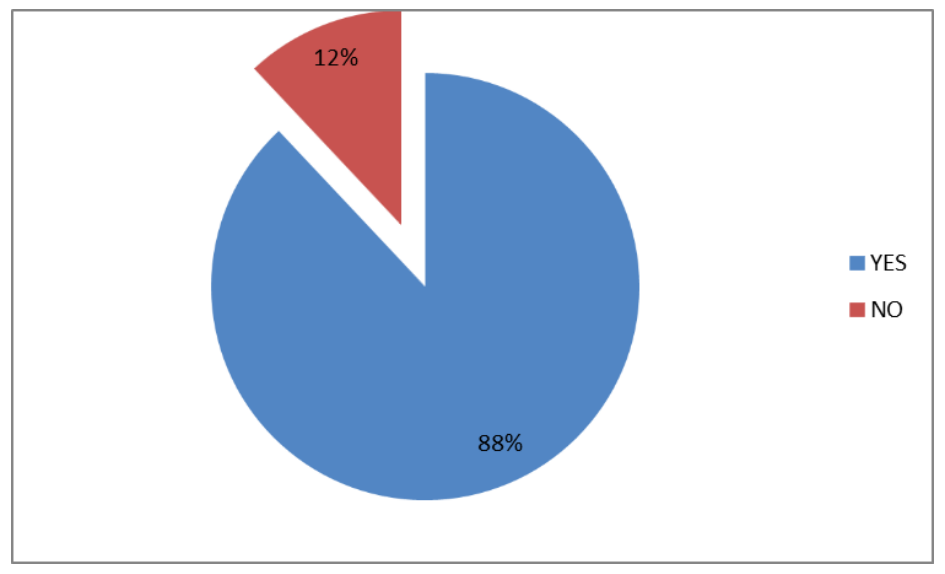

Figure 2 Disrupted/delayed academic calendar

Table 2 Effects of COVID-19 pandemic on mode of lecture delivery

\begin{tabular}{|c|c|c|c|c|c|c|c|}
\hline & & & \multicolumn{3}{|c|}{ Mode of lecture delivery } & \multirow[b]{2}{*}{ total } & \multirow[b]{2}{*}{$\begin{array}{l}\text { p- } \\
\text { value }\end{array}$} \\
\hline & & & online & $\begin{array}{l}\text { Normal physical } \\
\text { lectures with } \\
\text { COVID-19 protocols }\end{array}$ & $\begin{array}{l}\text { Normal classroom } \\
\text { teaching without } \\
\text { Covi-19 protocols }\end{array}$ & & \\
\hline \multirow{6}{*}{$\begin{array}{l}\text { Chi- } \\
\text { square }\end{array}$} & positive & Observed & 9 & 9 & 2 & 20 & \multirow{7}{*}{0.253} \\
\hline & postuve & expected & 6.8 & 8.6 & 4.6 & 20 & \\
\hline & $\%$ impact & & $45 \%$ & $45 \%$ & $! 0 \%$ & $100 \%$ & \\
\hline & \multirow{2}{*}{ negative } & Observed & 25 & 34 & 34 & 80 & \\
\hline & & expected & 27.2 & 34.4 & 34.4 & 80 & \\
\hline & \%impact & & $31.3 \%$ & $42.5 \%$ & $26.3 \%$ & $100 \%$ & \\
\hline total & $\begin{array}{l}\text { Observed/ } \\
\text { expected }\end{array}$ & & $\begin{array}{c}34 \\
(34 \%)\end{array}$ & $43(43 \%)$ & $23(23 \%)$ & $\begin{array}{c}100 \\
(100 \%)\end{array}$ & \\
\hline
\end{tabular}

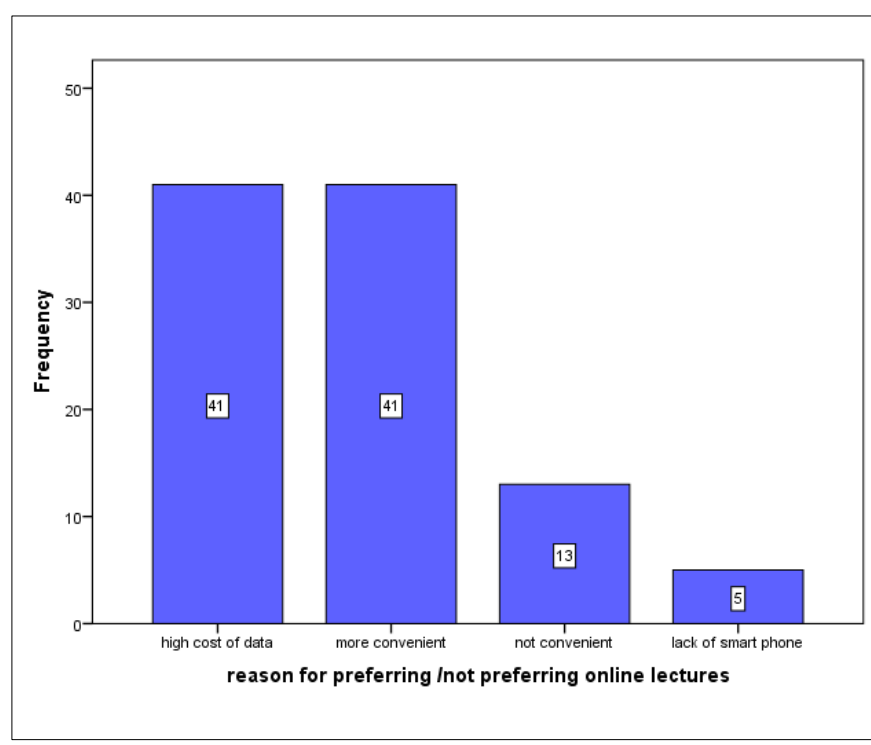

Figure 3 Factors affecting choice of online lectures 
Table 3 Effects of COVID 19 on Radiography Students and Staff of Nnamdi Azikiwe University

\begin{tabular}{|c|c|c|c|c|c|c|c|c|}
\hline \multirow[b]{2}{*}{$\mathbf{S} / \mathbf{N}$} & \multirow[b]{2}{*}{ Parameters } & \multicolumn{3}{|c|}{ responses from respondents } & \multirow[b]{2}{*}{$\begin{array}{l}\text { Chi-sq } \\
\text { Value }\end{array}$} & \multicolumn{3}{|c|}{ chi-square test } \\
\hline & & Yes (\%) & No $(\%)$ & $\begin{array}{l}\text { Not } \\
\text { sure } \\
\text { F(\%) }\end{array}$ & & $\begin{array}{l}\text { Likelihood } \\
\text { ratio }\end{array}$ & df & $\begin{array}{l}p \text { - } \\
\text { value }\end{array}$ \\
\hline 1 & $\begin{array}{l}\text { Change of attitude to infection } \\
\text { control was better during } \\
\text { pandemic than before }\end{array}$ & $81(81) \%$ & $\begin{array}{c}19 \\
(19 \%)\end{array}$ & - & 0.585 & 0.555 & 1 & 0.456 \\
\hline 2 & $\begin{array}{l}\text { Death of lecturers, students or } \\
\text { staff due of COVID-19 } \\
\text { pandemic }\end{array}$ & - & $\begin{array}{c}100 \\
(100 \%)\end{array}$ & -- & 0.355 & 0.352 & 1 & 0.557 \\
\hline 3 & $\begin{array}{l}\text { I have good access to funds to } \\
\text { finance my Radiography } \\
\text { education during the COVID- } \\
19 \text { pandemic }\end{array}$ & $3(3 \%)$ & $\begin{array}{c}97 \\
(97 \%)\end{array}$ & - & 0.344 & 0.303 & 1 & 0.652 \\
\hline 4 & $\begin{array}{l}\text { COVID-19 affected students } \\
\text { and lecturers attendance to } \\
\text { classes }\end{array}$ & $91(91 \%)$ & $9(9 \%)$ & - & 0.031 & 0.00 & 1 & 0.863 \\
\hline 5 & $\begin{array}{l}\text { COVID-19 pandemic } \\
\text { negatively affected students' } \\
\text { academic performance }\end{array}$ & $85(85 \%)$ & $\begin{array}{c}15 \\
(15 \%)\end{array}$ & - & 0.31 & 0.30 & 1 & 0.863 \\
\hline
\end{tabular}

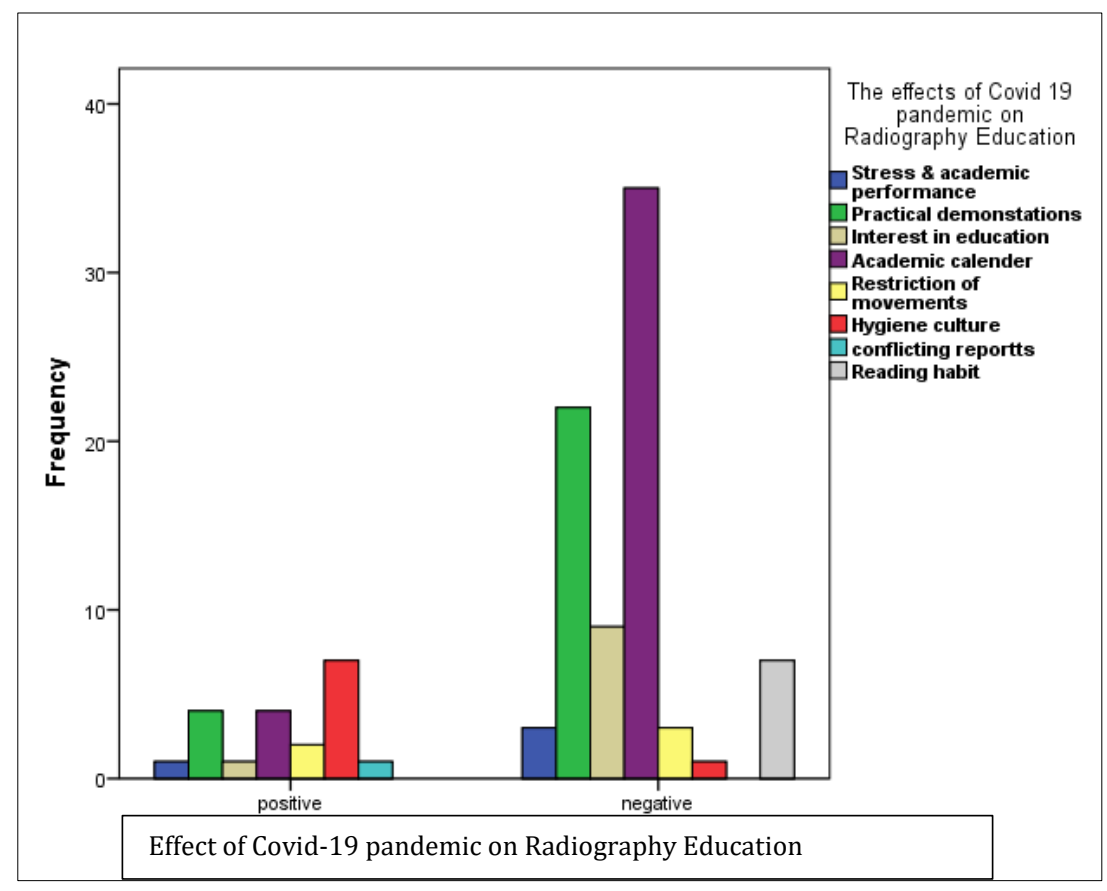

Figure 4 Effects of COVID-19 pandemic on Radiography education at Nnamdi Azikiwe University

Thirty- four percent $(n=34), 43 \%(n=43)$ of the respondents stated that they had online lectures and normal physical lectures observing COVID-19 protocols, while $23 \%(\mathrm{n}=23)$ had physical lectures without observing COVID-19 protocols respectively (Table 2).

Thirty-two percent $(n=32)$ of the respondents preferred to continue with online lectures while $47 \%$ ( $n=47)$ does not prefer online lectures and $21 \%(\mathrm{n}=21)$ were undecided (figure 3$)$. 
COVID-19 pandemic insignificantly affected students' academic performance, attendance to classes as well as caused a positive change of attitude to infection control by $91 \%, 85 \%, 81 \%$ respectively (Table 3).

The greatest effects of the COVID-19 pandemic on the university was that it affected the academic calendar and practical demonstrations negatively but had a positive effect on the hygiene culture (figure 4).

However, all the variable studied showed net significant effect on Radiography education but only the enthronement of better hygiene culture and inadequate/lack of practical demonstrations had significant effects on Radiography education ( $\mathrm{p}=0.00076)$ at Nnamdi Azikiwe University on post hoc analysis (Table 4).

Table 4 Post-Hoc: Effects of COVID-19 pandemic on Radiography education at Nnamdi Azikiwe University

\begin{tabular}{|c|c|c|c|c|}
\hline & $\begin{array}{l}\text { Parameters having effects on } \\
\text { Radiography education }\end{array}$ & Chi-square & positive & negative \\
\hline \multirow{5}{*}{1} & \multirow{5}{*}{$\begin{array}{l}\text { Many lectures were rushed over a short } \\
\text { time after lockdown and affected } \\
\text { students assimilation/understanding of } \\
\text { topics taught }\end{array}$} & observed & 1 & 3 \\
\hline & & expected & 8 & 3.2 \\
\hline & & Adjusted residual & 3 & -3 \\
\hline & & $\%$ effect & $25 \%$ & $75 \%$ \\
\hline & & $\mathrm{p}$-value & 1.00 & 1.00 \\
\hline \multirow{5}{*}{2} & \multirow{5}{*}{ Stress and academic performance } & observed & 1 & 3 \\
\hline & & expected & 8 & 3.2 \\
\hline & & Adjusted residual & 3 & -3 \\
\hline & & $\%$ effect & $5.0 \%$ & $3.8 \%$ \\
\hline & & p-value & 1.00 & 1.00 \\
\hline \multirow{5}{*}{3} & \multirow{5}{*}{ Practical demonstrations } & Observed & 4 & 22 \\
\hline & & Expected & 5.2 & 20.8 \\
\hline & & Adjusted residual & -0.7 & 0.7 \\
\hline & & $\%$ effect & $5.0 \%$ & $11.3 \%$ \\
\hline & & $\mathrm{p}$-value & 0.99 & 0.99 \\
\hline \multirow{5}{*}{4} & \multirow{5}{*}{ Interest in education } & observed & 1 & 9 \\
\hline & & expected & 2.0 & 8.0 \\
\hline & & Adjusted residual & -8 & 8 \\
\hline & & $\%$ effect & $20.0 \%$ & $27.5 \%$ \\
\hline & & p-value & 1.00 & 1.00 \\
\hline \multirow{5}{*}{5} & \multirow{5}{*}{ Restriction of movement } & observed & 2 & 3 \\
\hline & & expected & 1.0 & 4.0 \\
\hline & & Adjusted residual & 1.1 & -1.1 \\
\hline & & $\%$ effect & $10 \%$ & $3.8 \%$ \\
\hline & & p-value & 0.99 & 0.99 \\
\hline \multirow{3}{*}{6} & \multirow{3}{*}{ Hygiene culture } & observed & 7 & 1 \\
\hline & & expected & 1.6 & 6.4 \\
\hline & & Adjusted residual & 5.0 & -5.0 \\
\hline
\end{tabular}




\begin{tabular}{|c|c|c|c|c|}
\hline & & $\%$ effect & $35 \%$ & $1.3 \%$ \\
\hline & & p-value & $* 0.00076$ & $* 0.00076$ \\
\hline \multirow{5}{*}{7} & \multirow{5}{*}{$\begin{array}{l}\text { Psychological effects and confusion due } \\
\text { to conflicting reports from the } \\
\text { authorities }\end{array}$} & observed & 1 & 0 \\
\hline & & expected & 0.2 & 0.8 \\
\hline & & Adjusted residual & 2.0 & -2.0 \\
\hline & & $\%$ effect & $5 \%$ & $0 \%$ \\
\hline & & p-value & 0.78 & 0.78 \\
\hline \multirow{5}{*}{8} & \multirow{5}{*}{ Reading habit } & observed & 0 & 7 \\
\hline & & expected & 1.4 & 5.6 \\
\hline & & Adjusted residual & -1.4 & 1.4 \\
\hline & & $\%$ effect & $0.0 \%$ & $8.8 \%$ \\
\hline & & $\mathrm{p}$-value & 0.96 & 0.96 \\
\hline \multirow{5}{*}{9} & \multirow{5}{*}{ Academic calendar } & observed & 4 & 35 \\
\hline & & expected & 7.8 & 31.2 \\
\hline & & $\%$ effect & $20.0 \%$ & $43.8 \%$ \\
\hline & & Adjusted residual & -1.9 & 1.9 \\
\hline & & p-value & 0.82 & 0.82 \\
\hline
\end{tabular}

*Significant difference at $\mathrm{p}<0.005$, adjusted alpha $(\alpha)=0.0031)$

\section{Discussion}

The COVID-19 pandemic lockdown paralyzed socio-economic and educational activities in Nigeria, especially at the Nnamdi Azikiwe University. Majority (88\%) of the respondents asserted that their academic calendar for the year was delayed and disrupted because semester academic activities and examinations were postponed indefinitely and schools were closed due to the COVID-19 pandemic. The coronavirus lockdown lasted for more than five months during which students were idle at home with attendant consequences and this may delay or unnecessarily prolong the time of graduation of the students. This invariably cut short the expectations of the students, their families, guardians, and the society at large.

The prolonged stay at home may have resulted in other negative effects of the COVID -19 pandemic on the students and their education such as loss of interest in education, poor reading habits and low levels of social interactions sequel to movement restrictions even after resumption of academic activities following the lockdown. The delayed or disrupted academic calendar translated into a loss of academic/study time and rushing of several lectures over a short time, and undue stress which had negative effects on students' assimilation of subjects and academic performance (Tables 3 and 4). A related study established that man being a social animal interact and acquire various social behavior and characteristic outside the home. As a result, the long period of the lockdown had social, academic and psychological consequences on the students' [21]. Also, the World Bank posited that in addition to keeping 1.6 billion students out of school as of April 2020, the students were not able to learn during the COVID-19 pandemic lockdown. It further stated that a 5 months closure of schools led to a loss of 0.6 years of school work adjusted for quality [22]. Another related study also agrees with the findings of the present study and stated that the COVID-19 pandemic and lockdown means loss of academic period for university student which translates to indirectly prolonging the year of graduation [23].

We found out that online lectures suddenly became much sought out for among lecturers and students unlike what was obtainable before the COVID-19 pandemic. This is quite commendable because of the benefits of online lectures. The respondents especially postgraduate students explained that they can easily have their lectures at the comfort of their homes anywhere anytime (figure 3). Despite the fact that both online and classroom teachings with observance of COVID-19 protocols had a positive impact of $45 \%$ on Radiography education during the pandemic, $10 \%$ of the respondents confirmed that conventional classroom teachings without observing COVID-19 protocols like social distancing, use of face shield with regular washing/sanitizing of hands still took place (Table 2).This 
International Journal of Science and Research Archive, 2021, 03(01), 082-092

underscores the need for more COVID-19 enlightenment/education programs for students and lecturers as well as regular monitoring to ensure total compliance to the COVID -19 protocols/regulations. Similar findings have been reported by Rasila et al (2020) [24] among community members in South Africa but contrary to the findings of Von Soest et al (2020) [25] among adolescents in Oslo where 84\% compliance was recorded. The difference between the present study and the earlier study is attributed to differences in the population studied, enforcement, trust, and acceptance of the COVID-19 regulations. This means that physical classroom lectures were the dominant method of teaching during the COVID -19 pandemic. The reasons for the predominance of physical classroom lectures can be traced to the fact that it involves physical interaction between the students and lecture rs at no extra cost to either the lecturers or students. It also provides a platform for practicals and demonstrations of difficult ideas and concepts. This has been collaborated in a related study [23]. The scholars maintained that physical classroom lectures will remain relevant during the period of the COVID-19 pandemic especially in Nigeria due to the problems associated with other modes of teaching. While some institutions adopted virtual learning even before the reopening of schools with perceived challenges, others adopted physical contact teaching but with regular hand washing, sanitizing, temperature checks using infra-red thermometers and social distancing. The challenges of adopting virtual learning in Nigeria at that time were lack of facilities to run the online classes, poor/lack of electricity supply especially in the rural areas, poor internet connectivity, high cost of purchasing mobile data, computers or smartphones as well social inequality. Our study also revealed that postgraduate students prefer online lectures because it is more convenient for them since majority of them were off-campus and come from different parts of the country in addition to the COVID-19 pandemic. Majority of the undergraduate students do not prefer online lectures because of the high cost of data for internet connectivity as well as lack of smartphones (figure 3). They also complained that online lectures were not convenient for them probably because they were not technically oriented to handle it, issues with the timing of the lectures and internet network problems. A related study agreed with the findings of this study but added that other challenges of online education in Nigeria during the pandemic includes lack/poor electricity supply, time consuming, difficulty in assessing students, lack of direct communication between teaches and students and difficulty in closing the gap between slow and fast learners [23].

Moreover, we found out that conflicting reports from the authorities especially from the government had some effects on the psyche and education of the students. Some state Governors and some individuals in positions of respectable authorities categorically rejected the occurrence and effects of the COVID-19 pandemic in the country contrary to declarations of World Health Organizations and some government agencies. The conflicting reports from the authorities had psychological effects on the students which caused confusion and affected their educational orientation (figure 4). It also had negative effects on the trust and confidence of the staff a nd students of the university in the authorities with regard to their reports on the COVID-19 pandemic. This may also be one of the factors responsible for lack of total compliance to COVID -19 protocols and regulations among students and lecturers during lectures (Table 2).Recent research has demonstrated that trust and confidence in the government and health authorities increase the level of compliance to COVID-19 regulations [25]. Again we established that access to funds for the students to finance their education was adversely affected by the lockdown, restriction of movements as well as socio-economic activities due to COVID-19 pandemic and this has been collaborated by other studies [7, 18, 22]. Lack of personal protective equipment for Medical Radiographers at the hospitals where student Radiographers were expected to be present for tutelage coupled with the rising number of COVID-19 patients at the centers meant that admitting Radiography students in such conditions for clinical training will not be conducive. This may expose the students to COVID-19 infections in addition to other challenges. However, this was occasioned by some factors including poor budgetary allocation to education by the Nigerian Government which falls below the international benchmark by the United Nations Educational, Scientific and Cultural Organization (UNESCO) that 26\% of the national budget of member nations including Nigeria should be allocated to financing the education sector because of the importance of education to national development [16\}. Consequent upon this, the COVID-19 pandemic negatively affected students' practical demonstration sessions on campus as well as at the clinics/hospitals. (Figure 4). Students were reluctant to attend to radio-diagnostic clinics because of fear of COVID-19 infection and some of the few students' that attended were turned back because of the COVID-19 pandemic as well as a lack of personal protective accessories and equipment for the students'. This has been collaborated by related studies [18, 23, 26]. However, the most important positive effect of COVID-19 pandemic on Radiography education was the development of proper attitude to infection control and enthronement of better hygiene culture among staff and students of the university (Tables 3 and 4, figure 4).

Further statistical analysis indicate that poor attendance to lectures, low academic performance, poor access to education financing, lack of interest in education, conflicting reports from the authorities, delayed/disrupted academic calendar, inadequate clinical practical demonstrations, restriction of movements, increased stress, poor reading habits, infection control, and mode of lecture delivery had insignificant effects on Radiography education. Only the enthronement of better hygiene culture was found to be statistically significant on further analysis. This is attributed to the fact that staff and students of the university became more conscious of personal and group hygiene as a result 
of the COVID-19 pandemic. The authors were limited by logistics to embark on a holistic assessment of the effects of the COVID-19 pandemic on Tertiary educational institutions in Nigerian universities and Africa. It is therefore recommended that further research be conducted to assess the level of compliance to COVID-19 regulations by Radiographers in the society and establish the impact of the COVID-19 pandemic on the society, allied health professions, Radiography education, Research, and Radiography practice in all universities in Nigeria and Africa.

\section{Conclusion}

The positive effects of the COVID-19 pandemic was that it facilitated the development of a good attitude to infection control, better hygiene culture and promoted the interest of many students and lecturers in online lectures although the majority of the lectures were dominated by physical classroom teachings while the negative effects were low attendance to lectures, low academic performance, poor education financing, lack of interest in education, delayed/disrupted academic calendar, inadequate clinical practical demonstrations, low social interactions due to restriction of movements, increased stress, and poor reading habits. Only enthronement of better hygiene culture in both staff and students was statistically significant.

\section{Compliance with ethical standards}

\section{Acknowledgments}

We acknowledge Mrs Blessing Chidimma Okpaleke, for her wonderful secretarial assistance and Miss U. Ezechukwu for their contributions.

\section{Disclosure of conflict of interest}

All the authors declare no conflict of interest

\section{Statement of ethical approval}

Ethical approval (APPROVAL NO -NAU/FHST/2021/RAD113) for this study was obtained from the ethics committee of Nnamdi Azikiwe University, Faculty of Health sciences and technology, Nnewi campus.

\section{Statement of informed consent}

Informed consent was obtained from all individual participants included in the study.

\section{References}

[1] Amzat JK, Aminu VI, Kolo AA, Akinyele JA, Ogundairo, MC, Danjibo. Coronavirus outbreak in Nigeria: Burden and socio-medical response during first 100 days. Indian Journal of infectious diseases. 2020; 218-224.

[2] Sehgal M, Malhotra P, Sigh S, Madan R. Dentistry in COVID 19 Pandemic: emerging and upcoming challenges. Indian Journal of health sciences and care. 2020; 59-66.

[3] WHO, publication. WHO coronavirus (COVID 19) Dashord. 2020.

[4] Ajisegiri WS, Odusanya 00, Joshi R. COVID-19 Outbreak Situation in Nigeria and the Need for Effective Engagement of Community Health Workers for Epidemic Response. Global Biosecurity. 2020; 2(1).

[5] Fu Leiwen, Bingyi Wang, Tanwei Yuan, Xiaoting Chen, Yunlong Ao, Thomas Fitzpatrick, Peiyang Li, Yiguo Zhou, Yi-fan Lin, Qibin Duan, Ganfeng Luo, Song Fan, Yong Lu, Anping Feng, Yuewei Zhan, Bowen Liang, Weiping Cai, Lin Zhang, Xiangjun Du, Linghua Li, Yuelong Shu, and Huachun Zou. Clinical characteristics of coronavirus disease 2019 (COVID-19) in China: A systematic review and meta-analysis. Journal of Infection. 2020; 80(6): 656-665.

[6] Khan MS, Qurieshi MA, Haq I, Majid S, Akbar A. Seroprevalence of SARS-CoV-2 specific IgG antibodies in District Srinagar, northern India - a cross-sectional study [preprint]. Cold Spring Harbor: bioRxiv. 2020.

[7] Onyeaghala AA, Olajide I. Managing COVID 19 outbreak in Nigeria: matters arising. DeGruyter. 2020.

[8] Loannidis JPA. Infection fatality rate of COVID 19 infeered from seroprevalence data. Bulletin of the World Health Organization. 2021; 9: 19-33. 
[9] Dan-Nwafor C, Ochu CL, Kelly E, Oladejo J, Ilori E, Chukwuma U, Laura S, et al. Nigeria's public health response to the COVID-19 pandemic: January to May 2020, Journal of Global Health. 2020; 10(2): 020399.

[10] Nigeria Centre for Disease Control. COVID-19 Outbreak in Nigeria: Situation Reports. 2020.

[11] Anyanwu MU, Festus IJ, Nwobi OC, Jaja CI, Ogutu JW. A perspective of Nigeria preparedness, response and challenges to mitigating the spread of COVID-19. Challenges. 2020; 11(2): 22.

[12] Marbot O. Coronavirus Africa Map: Which Countries are Most at Risk? 2020.

[13] Nkengasong J, Iwasaki A, Victora C, Oh J, Gao GF, Agrawal A, Drosten C, Söderberg-Naucler C, López-Collazo E, Pollock AM, Viola A, Baker M. The Global Response to the COVID-19 Pandemic. Med (N Y). 2020; 1(1): 3-8.

[14] UNFPA publication. Corona virus disease (COVID-19) Pandedemic, UnFPA global respone plan. 2020.

[15] Obiakor t, Adeniran A. Cocid 19: impending situation threatens to deepen Nigeria'seducationcrisis. Publication by centre for the study of economies in Africa. 2020.

[16] Bassey OE, Peter SU. "Education Expenditure and Access to Education: Case Study of United Nations Educational, Scientific and Cultural Organization Declaration in Nigeria," International Journal of Economics and Financial Issues, Econjournals. 2017; 7(5): 290-298.

[17] Okwosa M, Modibbo MH. Education financing in nigeria and impact of COVID 19 pandemic. GPE publications. 2020.

[18] Ogolodom MP, Mbaba AN, Nwodo VK, Ohagwu CC, Chiegwu HU, Akram M, Ugwuanyi DC, Ikamaise VC, Okpaleke MS, Anakwue AC, Eze JC, Egbeyemi 00, Sidi M, Eja-Egwu UN. The Impact of COVID-19 Pandemic on Academic and Professional Development Programmes Organized by the Radiographers Registration Board of Nigeria. Journal of biomedical sciences. $2020 ; 10(1): 47-50$.

[19] Sangoseni O, Hellman M, Hill C. Development and validation of a questionnaire to assess the effect of online learning on behaviors, attitude and clinical practices of physical therapists in United States regarding of evidencebased practice. Internet Journal of Allied Health Science Practice. 2013; 11: 1-12.

[20] Bolarinwa OA. Principles and methods of validity and reliability testing of questionnaires used in social and health science researches. Nigeria Postgraduate Medical Journal. 2015; 22: 195-201.

[21] Ludvigsson JF. Systematic review of COVID-19 in children shows milder cases and a better prognosis than adults. Acta Paediatr. 2020.

[22] World Bank publication. COVID-19 Could Lead to Permanent Loss in Learning and Trillions of Dollars in Lost Earnings. 2020.

[23] Alaba TA, Oyelade EA. Impact of COVID-19 on the Nigerian Educational System: Strengths and Challenges of Online/Virtual Education. Asian Journal of Education and Social Studies. 2020; 13(1): 26-35.

[24] Rasila BN, Mashau TS, Obadire OS. Levels of adherence to covid-19 regulations and protocols by community members during lockdown alert 3 in the Limpopo Province, South Africa. African Journals Online. 2021; 18(4).

[25] Von Soest T, Pedersen W, Bakken A, Sletten MA. Compliance with infection control rules among adolescents in Oslo during the COVID-19 pandemic, Tidsskr or Laegeforen. 2020; 140(10).

[26] Pratico AD. COVID-19 pandemic for Pediatric Health Care: disadvantages and opportunities. Pediatric Research. 2021; 89: 709-710.

\section{Author Biography}

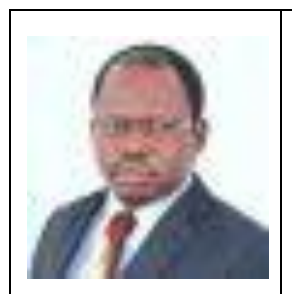

Dr Michael Sunday Okpaleke is a great researcher. He holds a Bachelors (Bsc-Hons), Master of science (Msc) and a Doctor of philosophy (PhD) in Radiography and Radiological Sciences as well as a Masters of Businnes Administration from famous Universities in Nigeria. A seasoned administrator and the second substantive Registrar /CEO of the Radiographers Registration Board of Nigeria, He is happily married with children and lives in Abuja, Nigeria. 